Research Article

\title{
Anticonvulsant effect of Rosa damascena in pentylenetetrazole and maximal electroshock induced convulsions in albino rats
}

\author{
Hemapriya Tirupathi*, Padmavathi Golla
}

Department of Pharmacology, Sri Padmavathi Medical College for Women, Tirupathi, Andhrapradesh, India

Received: 09 July 2016 Accepted: 09 August 2016

\section{*Correspondence to:}

Dr. Hemapriya Tirupathi, Email: hemapriyatirupathi@ gmail.com

Copyright: (C) the author(s), publisher and licensee Medip Academy. This is an openaccess article distributed under the terms of the Creative Commons Attribution NonCommercial License, which permits unrestricted noncommercial use, distribution, and reproduction in any medium, provided the original work is properly cited.

\begin{abstract}
Background: Rosa damascena mill L (Rosa damascena) is an ornamental plant that has several therapeutic (such as sedative and hypnotic) effects. It also heals depression, grief, nervous stress and tension. In the present study we evaluated Anticonvulsant like effect of Rosa damascena in pentylenetetrazole (PTZ) and MES induced convulsions in albino rats.

Methods: MES model: rats were divided into 4 groups of 6 rats each. Group-I received $0.5 \%$ normal saline, group-II (standard) received phenytoin $25 \mathrm{mg} / \mathrm{kg}$, group-III ,IV received low dose $(200 \mathrm{mg} / \mathrm{kg})$ and high dose $(400 \mathrm{mg} / \mathrm{kg})$ of rosa damascena respectively orally convulsions were produced in all groups by giving maximum electric shock of $150 \mathrm{~mA}$ for $0.2 \mathrm{sec}$ after 1 hour of giving test and standard drugs orally. Tonic clonic seizures were produced after giving electric shock .recovery time was noted. The percentage of inhibition of convulsions by drugs was measured and compared between the control, standard and test.

PTZ model: rats were divided and test drugs were given same as above model but standard drug was sodium valporate $(200 \mathrm{mg} / \mathrm{kg})$. Convulsions were induced by giving the pentylenetetrazole IP 1hour after giving test and standard drugs intra-peritonelly. The onset of convulsions, duration of action and type of seizures were noted and compared between standard and test groups.

Results: In MES Model, aqueous extract of Rosa damascena significantly $(\mathrm{p}<0.001)$ decreased the duration of tonic clonic seizures and recovery time. In PTZ model the onset of seizures was delayed $(\mathrm{p}<0.001)$ with low and high doses and the duration of convulsions was reduced effectively $(\mathrm{p}<0.001)$. Type of seizure was controlled in initial phase and number of seizures was also reduced.

Conclusions: Rosa damascena was shown anticonvulsant property in both MES and PTZ animal models.
\end{abstract}

Keywords: Rosa damascena, Rats, Phenytoin, Sodium valporate

\section{INTRODUCTION}

Rosa damascena mill L (Rosa damascena), commonly known as Damask rose, is one of the most important species of Rosaceae family which is a well-known ornamental plant in the world that has been referred to as the king of flowers. ${ }^{1-3}$

The major cultivation areas of Rosa damascena in Iran are Kashan, Fars and Azerbaijan, among them Kashan is the most famous one. ${ }^{4}$ The most therapeutic effects of Rosa damascena in ancient medicine are treatment of abdominal and chest pain, strengthening the heart, treatment of menstrual bleeding and digestive problems and reduction of inflammation, especially of the neck. ${ }^{5,6}$
North American Indian tribes used a decoction of the root of Rosa damascena plant as a cough remedy to ease children's cough. $^{7}$ This plant is also used as a gentle laxative8. Rose oil heals depression, grief, nervous stress and tension. It helps in the reduction of thirst, old cough, special complaints of women, wound healing, and skin health. Vapour therapy of rose oil is helpful for some allergies, headaches, and migraine. ${ }^{8,9}$

Several components were isolated from flowers, petals and hips (seed-pot) of Rosa damascena including terpenes, glycosides, flavonoids and anthocyanins. This plant contains carboxylic acid, myrcene, vitamin C, kaempferol and quarcetin. ${ }^{10-16}$ The essential oil of Rosa damascena in acute pentylenetetrazole (PTZ)-induced seizure in rats, delays the start of epileptic seizures and 
decrease the duration of tonic-clonic seizures (stage 4). In chronic model of PTZ induced seizure, this plant also caused prolongation of latent periods before tonic clonic generalized seizures. It is also suggested that essential oil of Rosa damascena retarded the development of behavioural seizures in amygdale electrical kindling and possesses the ability to counteract kindling acquisition. The aqueous and ethanolic extracts of Rosa damascena have potentially anticonvulsant effect in PTZ induced seizure and MES model in mice. ${ }^{17-19}$

\section{METHODS}

\section{Plant material and preparation of extract of Rosa damascena}

Plants were collected from Nellore district, Andhra Pradesh, India. The plant was authenticated for its correct botanical identity by the chief botanist.

The aqueous extract of plant was prepared as follows:

400 gms of the chopped, dried flowers of plant were extracted with $2 \mathrm{~L}$ of distilled water by the soxlet apparatus. The solvent used for obtaining extract was evaporated by a rotator evaporator under reduced pressure at $50{ }^{\circ} \mathrm{C}$. The final extracted material weighed $10 \mathrm{gm}$ that was prepared by dissolving final product in distilled water. $^{20}$

\section{Animals}

Swiss albino mice weighing 25-30 grams of either sex were obtained from the central animal house of Narayana Medical College, Nellore. They were housed in standard polypropylene cages with paddy husk as bedding and kept under controlled room temperature $\left(21-23^{\circ} \mathrm{C}\right.$; relative humidity $60-70 \%$ ) in a 12 hours light-dark cycle. Animals were given a standard laboratory diet and water ad libitum. All experiments were performed between 09:00 am and 3:00 pm in order to minimize the effect of circadian rhythms. Animals were acclimatized to laboratory conditions one week prior to initiation of experiments.

\section{Method}

\section{The maximal electroshock (MES) induced convulsions}

Albino rats of either sex weighing from 180 to $200 \mathrm{gm}$ were used in this study. These were acclimatized to their environment for one week prior to experimentation. The animals were randomly distributed into four different groups. Each experimental group consists of a 6 animals. Each group is caged separately after recording its body weight and the animals are marked with marker for identification.

\section{Equipment}

Electroconvulsiometer (INCO company), ear clip electrodes ( $150 \mathrm{~mA}$ current for $0.2 \mathrm{sec})$, stop watch.

\section{Grouping of animals}

For the experimental animals were weighed, and randomly divided into four groups, each group consisting of six animals.

- Group I - Control group-saline $0.5 \mathrm{ml}$

- Group II - Standard group- Phenytoin - $25 \mathrm{mg} / \mathrm{kg}$

- Group III - Test group- Rosa damascena - 200 mg/kg

- Group IV - Test group - Rosa damascena - 400 $\mathrm{mg} / \mathrm{kg}$.

\section{Procedure}

MES seizures were electrically induced by means of an Electroconvulsiometer $150 \mathrm{~mA}$ current is delivered transauricularly (ear clips) for $0.2 \mathrm{sec}$. This current intensity elicited complete tonic hind limb extension (THE) in animals. For measuring various parameters, rats were placed in a clear rectangular plastic cage with an open top, permitting full view of the animals' motor responses to the seizures. Later each animal was then individually observed for 2 hours to study convulsive effects on general behaviour. Suppression of tonic hind limb extension was taken as a measure of efficacy of the drugs in this test. Anti-convulsive drugs abolish or reduce the duration of time of tonic hind limb extension phase of MES. After 30 minutes of administering respective drugs of those particular groups, MES was induced. Onset and duration of time for tonic hind limb extension (THE) was noted and compared the in all groups.

\section{Pentylenetetrazole induced seizures ${ }^{21}$}

Albino rats of either sex weighing from 150 to $200 \mathrm{gm}$ used in this study. These were acclimatized to their environment for one week prior to experimentation. The animals were randomly distributed into four different groups. Each experimental group will consist of a 6 animals. Each group is caged separately after recording its body weight, and the animals were marked with marker for identification.

\section{Grouping of animals}

The experimental animals were weighed, and randomly divided into four groups, each group consisting of six animals.

- Group I - Control group - saline $0.5 \mathrm{ml}$

- Group II - standard group- Sodiumvalporate - 200 $\mathrm{mg} / \mathrm{kg}$

- Group III - Test group- Rosa damascena - 200 mg/kg

- Group IV - Test group - Rosa damascena - 400 $\mathrm{mg} / \mathrm{kg}$. 


\section{Principle}

Pentylenetetrazole is a central nervous system stimulant. It produces jerky type of clonic convulsions in rat. The convulsive effect of this drug is considered to be analog to petitmal type of convulsions in man. Pentylenetetrazol has been reported to act through GABA- benzodiazepine receptor mechanisms in the brain. It is widely used as a tool in experimental pharmacology to study convulsant and anticonvulsant action of drugs.

\section{Procedure}

Rats were divided into 4 groups; each group consisted of 6 rats. Rats were chosen by giving pentylenetetrazole. Only those rats which produced jerky movements of the whole body were chosen for the study. After 30 minutes of administering respective drugs of those particular groups, pentylenetetrazole was injected to the animals and the onset and duration time for clonic convulsions are noted in all the groups. Later the onset and duration time for clonic convulsions in all groups was compared.
All the experimental procedures and protocols used in this study were carried out according to the guidelines of institutional animal ethical committee and Ethical committee clearance was obtained from IAEC (Institutional Animal Ethics Committee).

\section{RESULTS}

The time of onset and duration of tonic hind limb extension for control group was 2.00 \pm 0.196 and $11.15 \pm 0.48$ respectively. For Rosa damascena the onset and duration of the for dose of $200 \mathrm{mg} / \mathrm{kg}$ was $2.50 \pm 0.196$, $10.20 \pm 0.27$ and for $400 \mathrm{mg} / \mathrm{kg}$ was $4.51 \pm 0.20,8.41 \pm 0.28$ respectively. The tonic hind extension was totally abolished in standard group. As compared to control group Rosa damascena in the dose of $400 \mathrm{mg} / \mathrm{kg}$ significantly $(* * * \mathrm{p}<0.001)$ reduced the onset and duration of tonic hind extension, but less when compared to standard group.

Table 1: Maximal electroshock seizure (MES) induced convulsions.

\begin{tabular}{|llll|}
\hline Groups & Treatment groups & $\begin{array}{l}\text { Onset of tonic hind limb } \\
\text { extension (in sec) }\end{array}$ & $\begin{array}{l}\text { Duration of tonic hind } \\
\text { limb extension (in sec) }\end{array}$ \\
\hline Control & Normal saline & $2.00 \pm 0.196$ & $11.15 \pm 0.48$ \\
\hline Standard (phenytoin) & $25 \mathrm{mg} / \mathrm{kg}$ & Totally abolished & Totally abolished \\
\hline Rosa damascena & $200 \mathrm{mg} / \mathrm{kg}$ & $2.50 \pm 0.196^{* * *}$ & $10.20 \pm 0.27 * * *$ \\
\hline Rosa damascena & $400 \mathrm{mg} / \mathrm{kg}$ & $4.51 \pm 0.20^{* * *}$ & $8.41 \pm 0.28^{* * * *}$ \\
\hline *** p $<0.001$ compared to control group & &
\end{tabular}

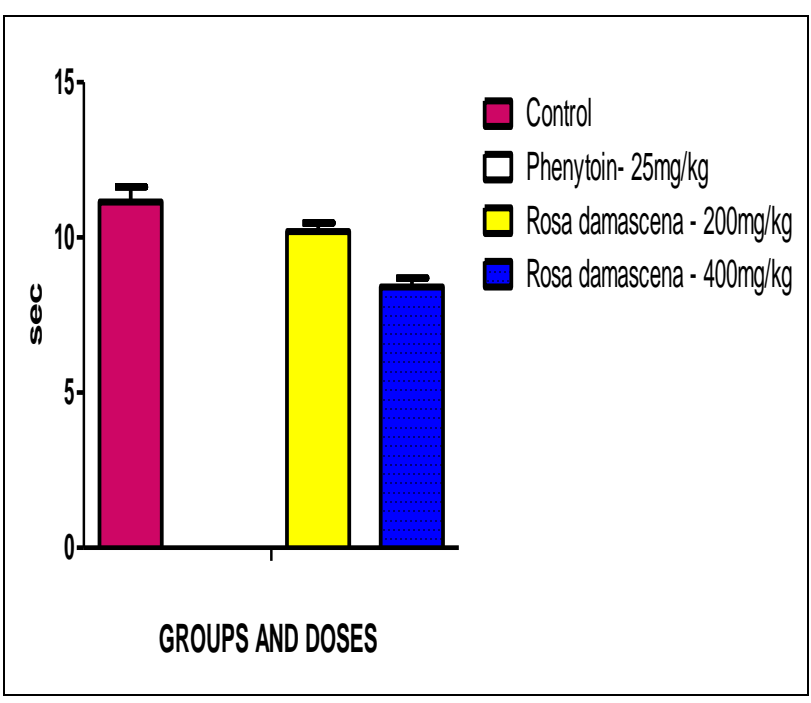

Figure 1: Mean time for onset of the tonic hind limb extension.

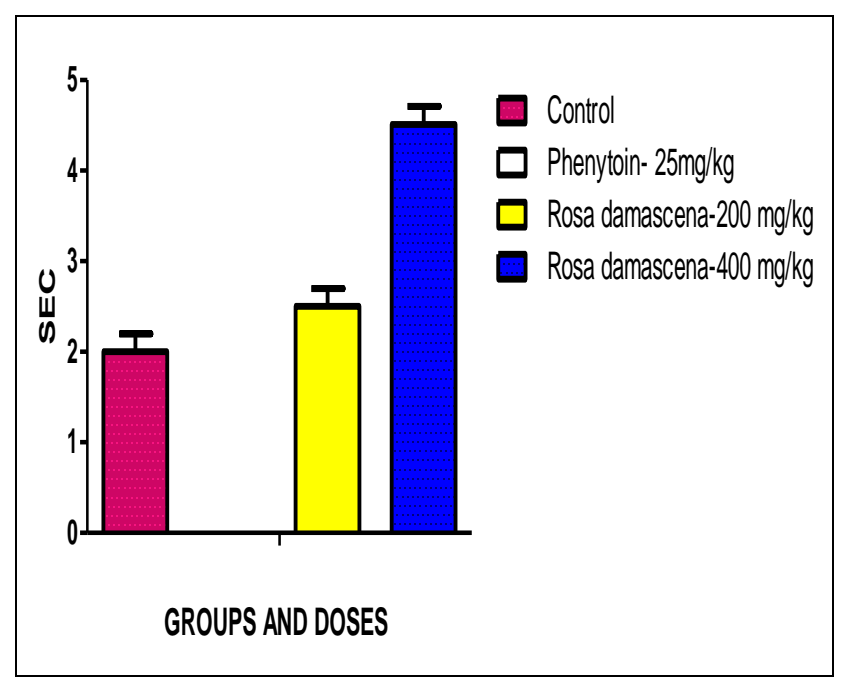

Figure 2: Mean time duration of the tonic hind limb extension. 
Table 2: PTZ induced convulsions.

\begin{tabular}{|llll|}
\hline Groups & $\begin{array}{l}\text { Treatment } \\
\text { Dose }(\mathrm{mg} / \mathrm{kg})\end{array}$ & $\begin{array}{l}\text { Onset of mean time for } \\
\text { jerks in minute (SD) }\end{array}$ & $\begin{array}{l}\text { Mean time duration jerks } \\
\text { in minute (SD) }\end{array}$ \\
\hline Control & Normal saline & $2.08 \pm 0.12$ & $46.70 \pm 1.79$ \\
\hline Standard & Sodium valproate $-200 \mathrm{mg} / \mathrm{kg}$ & $9.48 \pm 0.75^{* * *}$ & $22.36 \pm 1.38^{* * *}$ \\
\hline Rosa damascena & $200 \mathrm{mg} / \mathrm{kg}$ & $3.96 \pm 0.12 * * *$ & $39.14 \pm 1.92 * * *$ \\
\hline Rosa damascena & $400 \mathrm{mg} / \mathrm{kg}$ & $6.76 \pm 0.18^{* * *}$ & $33.30 \pm 1.90^{* * *}$ \\
\hline$* * * \mathrm{p}<0.001$ compared to control group. & &
\end{tabular}

The time of onset of jerks and duration of jerks for control group was $2.08 \pm 0.1$ and $46.70 \pm 1.79$. For sodium valproate the onset and duration of jerks was $9.48 \pm 0.75$ and 22.36 \pm 1.38 . Onset and duration of jerks for Rosa damascena for the dose of $200 \mathrm{mg} / \mathrm{kg}$ was $3.96 \pm 0.12$, $39.14 \pm 1.92$ and for $400 \mathrm{mg} / \mathrm{kg}$ is $6.76 \pm 0.18,33.30 \pm 1.90$ respectively.

As compared with control group Rosa damascena significantly $(* * * \mathrm{p}<0.001)$ delayed the onset and duration of convulsions induced by PTZ. Rosa damascena in the dose of $400 \mathrm{mg} / \mathrm{kg}$ significantly delayed the onset of clonic convulsions induced by PTZ, which is comparable with standard drug sodium valproate.

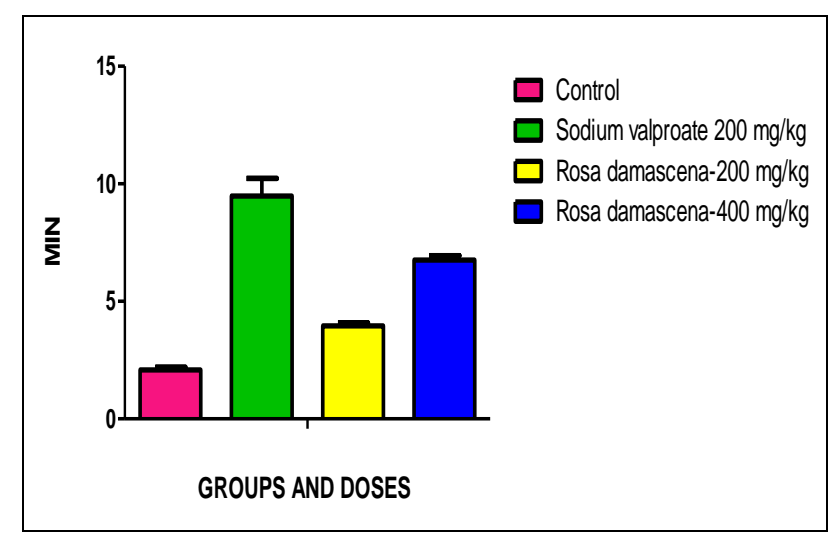

Figure 3: Mean time for onset of jerky movements.

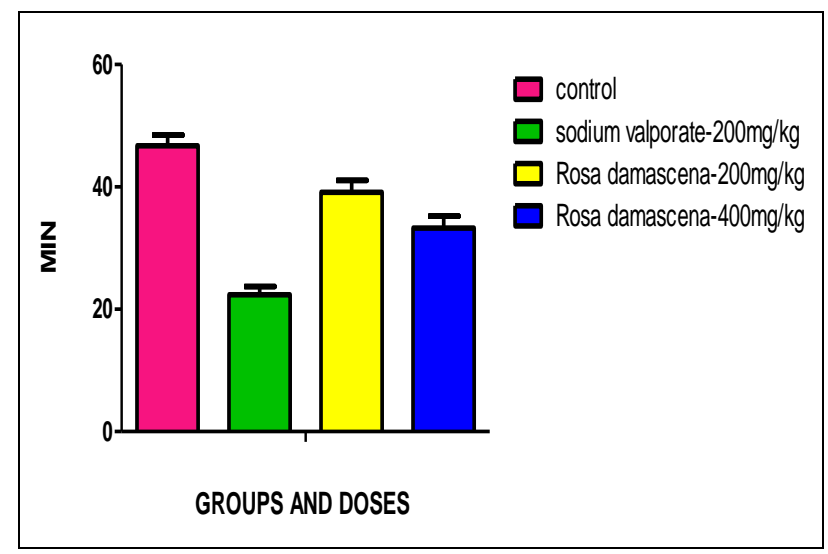

Figure 4: Mean time duration of jerky movements.

\section{DISCUSSION}

Pentylenetetrazol is a tetrazole derivative with consistent convulsive effect which acts by antagonising the inhibitory GABA ergic neurotransmission. PTZ test is used for screening of drugs effective in petitmal epilepsy.

Rosa damascena in the dose of $200 \mathrm{mg} / \mathrm{kg}$ and $400 \mathrm{mg} / \mathrm{kg}$ showed significant anti-epileptic activity in the seizures induced by pentylenetetrazole in a dose dependant manner compared to control group $(\mathrm{P}<0.001)$ indicating that it has anti-epileptic property however the antiepileptic activity was less than that of sodium valproate.

Rosa damascena increased the seizure threshold, the ability of Rosa damascena to both elevate seizure threshold and block PTZ-induced convulsions can be attributed to its modulatory effect on GABA neurotransmission. The probable mechanism of antiepileptic activity is by increasing the GABA ergic neurotransmission. As GABA is inhibitory neurotransmitter in brain increasing GABA levels supress the seizure activity in brain.

Our studies is supported by Hosseini $\mathrm{M}$ et al showed anticonvulsant activity of Rosa damascena in doses of $200 \mathrm{mg} / \mathrm{kg}$ in PTZ induced convulsions with respect to activity of $\mathrm{Na}+/ \mathrm{K}+, \mathrm{Mg} 2+$ and $\mathrm{Ca} 2+-$ ATPases in rat brain during pentylenetetrazole-induced epilepsy. All the three ATPases were elevated in different regions of brain during pre-treatment with Rosa damascena extracts in PTZ-induced epileptic animal and maintaining ionic equilibrium. $^{22}$

Maximal electric shock induced convulsions is a best suitable test for evaluating anti-epileptic properties of drugs, because it is the best-validated preclinical test that predicts drugs effective against generalized seizures of the tonic-clonic (grand mal) type.

In our study, Rosa damascena showed significant antiepileptic activity with $400 \mathrm{mg} / \mathrm{kg}$ compared to control group but has less when compared to that of standard drug phenytoin. At low dose i,e $200 \mathrm{mg} / \mathrm{kg}$, Rosa damascena showed antiepileptic property but it was not significant as compared to control. 
MES-induced tonic extension can be blocked by drugs that inhibit voltage dependent $\mathrm{Na}+$ channels, such as phenytoin, carbamazepine, and valproate (Macdonald and Kelly, Rogawski and Porter, White) and drugs that enhance GABA-A receptor-mediated inhibitory neurotransmission, such as benzodiazepines, phenobarbital and valproate (Macdonald and Kelly, Rogawski and Porter, White).

As MES is supressed by drugs that enhance GABA-A receptor-mediated inhibitory neurotransmission the probable mechanism of Rosa damascena to show activity in MES induced convulsion is through GABA- A mediated neurotransmission.

\section{CONCLUSION}

Anticonvulsant property is studied using MES induced convulsions and PTZ induced convulsion in rats. Rosa damascena was used in the dose of $200 \mathrm{mg} / \mathrm{kg}, 400$ $\mathrm{mg} / \mathrm{kg}$. Rosa damascena in the dose of $400 \mathrm{mg} / \mathrm{kg}$ showed more significant response than $200 \mathrm{mg} / \mathrm{kg}$ by decreasing the time for onset and duration of tonic hind limb extension.

Rosa damascena in both doses showed significant reduction in PTZ induced convulsions. The anticonvulsant activity of Rosa damascena in the doses of $200 \mathrm{mg} / \mathrm{kg}$ and $400 \mathrm{mg} / \mathrm{kg}$ is comparable with that of Sodium valproate.

The results showed more activity in PTZ induced convulsion suggesting that it could be very useful drug in absence seizure. The possible mechanism of anticonvulsant property is increase in GABAnergic neurotransmission in brain and maintaining of ionic equilibrium in brain by inhibiting $\mathrm{Na}+$ channels.

Further studies are required to explore its anticonvulsant activity and the probable mechanism of action and to isolate the active principles from them.

\section{ACKNOWLEDGEMENTS}

Authors would like to express my sincere gratitude to my advisor my HOD, DR. B. L. KUDAGI for the continuous support of my related research study, for his patience, motivation, and immense knowledge. His guidance helped me in all the time. I also thank full to my collegues Dr. Praveen, Dr. Padmavathi, Dr. Sujith who helped me for my research work. I dedicate my research work heartfully to my Parents.

Funding: No funding sources Conflict of interest: None declared

Ethical approval: The study was approved by the Institutional Ethics Committee

\section{REFERENCES}

1. Kaul VK, Singh V, Singh B. Damask rose and marigold: prospective industrial crops. J Med Aromat Plant Sci. 2000;22:313-8.

2. Nikbakh TA, Kafi M, Mirmasoudi M, Babalar M. Micropropagation of damask rose (Rosa damascena Mill.) cvs Azaran and Ghamsar. International J of Agriculture and Biology. 2005;7(4):535-8.

3. Mahmood N, Piacente S, Pizza C, Burke A, Khan AL, Hay AJ. The anti-HIV activity and mechanisms of action of pure com-pounds isolated from Rosa damascena. Biochem Biophys Res Commun. 1996;229:73-9.

4. Nikbakht A, Kafi M. A study on the relationships between Iranian people and damask rose (Rosa damascena) and its therapeutic and healing Properties. Acta Hort (ISHS). 2008;790:251-4.

5. Wood G, Bache F. The dispensatory of the United States of America, $4^{\text {th }}$ ed. Philadelphia: Griggand Elliot. 1839;8:80-6.

6. Buckle DR, Arch JRS, Boering NE, Foster KA, Taylor JF, Taylor SG, et al. Relaxation effect of potassium channel activators BRL 38227 and pinacidil on guinea-pig and human airway smooth muscle, and blockade of their effects by Glibenclamide and BRL 31660. Pulm Pharmacol. 1993;6:77-86.

7. Libster M. Delmar's integrative herb guide for nurses. Delmar Thamson Learning, Albany; 2002:360-370.

8. Zargari A. Medicinal plants. Tehran: Tehran University Press. 1992;1:281-4.

9. Momeni T, Shahrokhi N. Essential oils and their therapeutic actions. Tehran, Iran: Tehran University. Press. 1991;6:101-8.

10. Green M. The Rose. Aromatic thymes. 1999;1:11-5.

11. Oka N, Ikegami A, Ohki M, Sakata K, Yagi A, Watanabe N. Citronellyl disaccharide glycoside as an aroma precursor from rose flowers. Phytochemistry. 1998;47:1527-9.

12. Knapp H, Straubinger $M$, Fornari $S$, Oka $N$, Watanabe N. (S)-3,7-Dimethyl-5-octene-1,7-diol and related oxygenated monoterpenoids from petals of Rosa damascena Mill. J Agri Food Chem. 1998;46:1966-70.

13. Shieber A, Mihalev K, Berardini N, Mollov P, Carle R. Flavonol glycosides from distilled petals of Rosa damascena Mill. Z Naturforsch C. 2005;60:379-84.

14. Kumar N, Singh B, Kaul VK. Flavonoids from Rosa damascena Mill. Nat Prod Commun. 2006;1:623-6.

15. Delmar's LM. Integrative herb guide for nurses. Delmar thamson learning, Albany. 2002;2:360-70.

16. Mahmood N, Piacente S, Pizza C, Burke A, Khan AL, Hay AJ. The anti-HIV activity and mechanisms of action of pure com-pounds isolated from Rosa damascena. Biochem Biophys Res Commun. 1996;229:73-9.

17. Kheirabadi M, Moghimi A, Rakhshande H, Rassouli $\mathrm{MB}$. Evaluation of the anticonvulsant activities of 
Rosa damascena on the PTZ induced seizures in wistar rats. J Biol Sci. 2008;8:426-30.

18. Ashrafzadeh F, Rakhshandah H, Mahmoudi E. Rosa damascene oil: an adjunctive therapy for pediatric refractory seizer. Iranian journal of child neurology. 2007;1:13-7.

19. Kheirabadi M, Moghimi A, Rakhhande H, Rassouli MB. Evaluvation of the anticonvulsant activities of rosa damascena on PTZ induced seizures in wistar rats. Journal of biological sciences. 2008;8(2):42630 .
20. Dolati K, Rakhshandeh H, Shafei HN. Antidepressant-like effect of aqueous extract from Rosa damascena in mice Avicenna. Journal Phytomedicine Autum. 2011;1(2):91-7.

21. Trescher WH, Lesser RP. The epilepsies. In: Bradley WG, Daroff RB, Fenichel GM, Marsden CD. Neurology in clinical practice. $5^{\text {th }}$ edition. Philadelphia: Elsiever publication. 2008;18:1909-46.

22. Hosseini M, Rahbardar MG, Sadeghnia HR. Effects of different extracts of Rosa damascena on ptz induced seizures in mice. Journal of interogative medicine. 2011;9(10):1118-24.

Cite this article as: Tirupathi $\mathrm{H}$, Golla $\mathrm{P}$. Anticonvulsant effect of Rosa damascena in pentylenetetrazole and maximal electroshock induced convulsions in albino rats. Int J Basic Clin Pharmacol 2016;5:2071-6. 